\title{
REDESCRIPTION OF LITHOPHOTINA FLOCCOSA COCK. (MANTEODEA) WITH SOME NOTES ON THE MANTEOD WING VENATION
}

\author{
By A. G. Sharov \\ Paleontological Institute, Academy of Sciences, USSR, Moscow
}

Dr. G. M. Byers recently sent to me for study the wing of an insect from the Miocene deposits of Colorado. I determined this wing to be the hind wing of a manteod, close to Lithophotina floccosa Cock., which Cockerell described in 1908 from the same deposits. At my request and with the approval of Dr. Hugo Rodeck (University of Colorado Museum) Professor F. M. Carpenter brought the holotype of L. Aloccosa to Moscow with him at the time of his visit to the Paleontological Institute. A study of the holotype led me to the conclusion that the hind wing which Dr. G. M. Byers sent most probably belongs to the same species, i.e. L. floccosa. A comparison with the venation of the fore and hind wings of the living manteod Chaeteesa filata Burm., which belongs to the primitive relict family Chaeteesidae, confirms this. L. floccosa also ought to be referred to this family. Since the description of L. floccosa given by Cockerell is very short, and since drawings are lacking and the photograph in the article is poorly reproduced, a redescription of $L$. floccosa, with a description of the hind wing of this species, is given below.

\section{Family Chaeteesidae \\ Lithophotina floccosa Cock.}

Figure I

Lithophotina floccosa Cock., 1908, Canad. Ent., 40:343-344.

The fore wing of this species (Figure IA) was found in the Miocene deposits of Colorado (Florissant) at Station No. I4. The length of the wing is $21.5 \mathrm{~mm}$, the width $7 \mathrm{~mm}$. The wing is narrowed at the base. Sc is long, taking up more than two-thirds the length of the wing, ending at its widest portion. The branches of Sc close to the base of the wing have the character of cross-veins; in the center, together with the cross-veins which join them, they form a double row of cells; and close to the apex they take on the character of gently curving branches. At the apical portion of the

${ }^{1}$ Manuscript received by the editor July 21, 1962. The editor is indebted to Miss Helen Vaitaitis for the English translation of the article. 
wing, $\mathrm{R}$ has 4-5 branches in pectinated form, which are directed toward the fore margin. MA at the center of the wing length forms two branches, of which the fore branch divides again close to the apex, and the hind one forms two short branches at the very apex. The vein $\mathrm{MP}$ is merged with $\mathrm{CuA}$ and its base apparently forms one of the cross-veins. $\mathrm{MP}+\mathrm{CuA}$ dichotomizes and forms seven branches.

Between R, M and their branches there is a double row of cells. The anal portion in the holotype is missing; evidently it was torn off while the wing was being carried by currents of water before it was buried. The longitudinal and cross-veins are colored with brown pigment.

The hind wing (Figure IB) was found by G. M. Byers in July of 1953 in the same deposits at the Park County station. The length of the hind wing is $18 \mathrm{~mm}$. The different character of the venation of the fore and hind wings, and also the ratio of the length of the fore wing to the length of the hind wing of $L$. floccosa, is very close to that of Chaeteesa filata Burm. (Figure 2), which is the reason for placing the specimen of the hind wing found by G. M. Byers in the same species, i.e. L. floccosa.

Sc ends at a distance less than two-thirds of the length of the wing from the base. $\mathrm{R}$ has three oblique branches. $\mathrm{Rs}$ is simple and does not branch. $M$ is joined with $R$ only at the base of the wing, proximal to the beginning of MP. MA forms three branches in the same sequence as in the fore wing. MP has the character of a crossvein but is stronger in comparison with the other cross-veins. MP + $\mathrm{CuA}$ forms three branches. In the distal portion of the wing between the longitudinal veins there is a double row of cells. Both the longitudinal and the cross-veins are colored with brown pigment.

Although there is no doubt about the closeness of the Manteodea to the Blattodea, the interpretation of the venation of the former, particularly with respect to the hind wing, remains questionable (see Smart, I956, p. 550). In such cases the study of fossil material is extremely desirable, and the fossil representative of the Manteodea examined here actually permits a simple solution of some debatable questions on the venation of these insects. (See figure 2).

Chopard (1949) and Ragge (1955) find an independent RS in the fore wing of some Manteodea, the nature of which becomes clear upon examination of the fore wing of Lithophotina, where $\mathrm{R}$ has the same type of pectinated branching as in most Blattodea. In Chaeteesa, as Smart (1956) has correctly noted, the remains of these 
branches are short oblique veinlets on the end of R. In Mantis, Ameles and several other Manteodea only two of these branches are preserved, the hind one usually being mistaken for Rs.
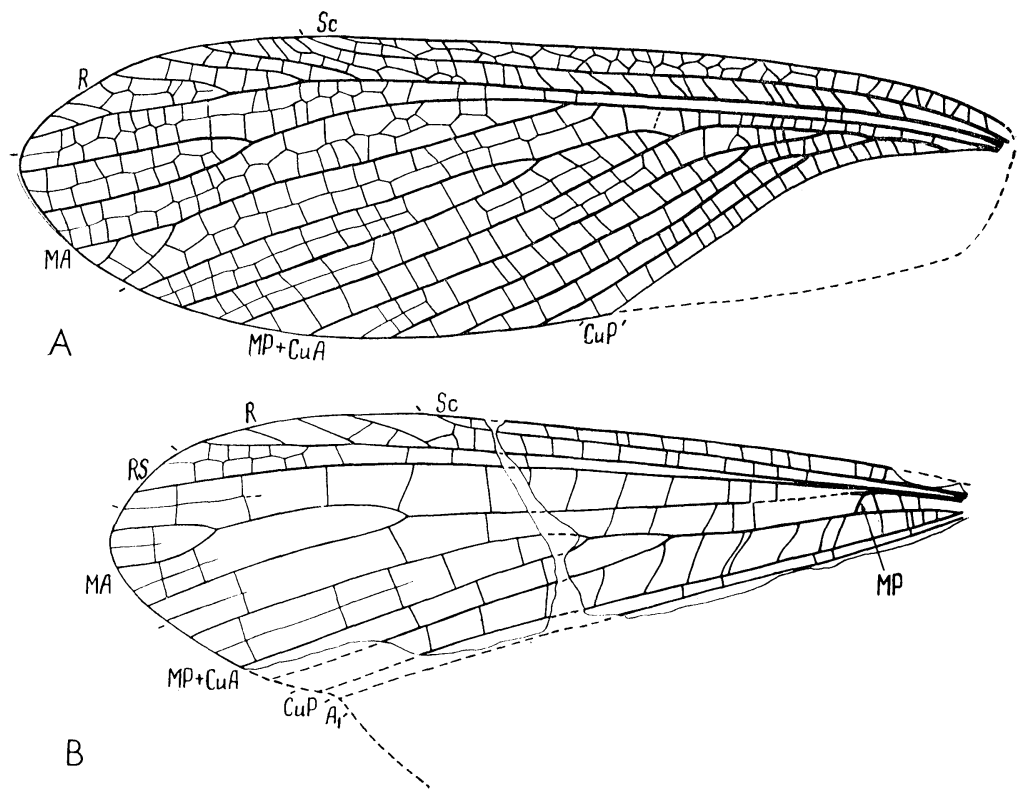

Fig. 1. Drawing of Lithophotina floccosa Cock.; A. Holotype (fore wing) ; B. Homeotype (hind wing).

The stem following $\mathrm{R}$ which is mistakenly identified in Blattodea and Manteodea as $\mathrm{M}$, in the opinion of the author, is this only in the proximal portion. Its distal portion together with the branches is really the fore branch of $\mathrm{M}$, i.e. MA, whereas the hind branch, $\mathrm{MP}$, is merged with $\mathrm{CuA}$. Only in some Paleozoic Blattodea (Archimylacris pruvosti Laur., Aphtoroblattina shottoni Laur.) is the base of MP in the fore wings represented as an oblique vein, which in the rest of the Blattodea and in all known Manteodea is missing or has the character of a cross-vein, just as has occurred in the evolution of the Plecoptera (Sharov, I960).

The peculiarities of the venation of the hind wing of $L$. floccosa confirm the correctness of the interpretation of $\mathrm{R}$ and $\mathrm{Rs}$ in the hind wings of the Manteodea proposed by Ragge (1955) on the basis of the study of the tracheation and accepted later by Smart (I956), although with some reservations (p. 550). In L. floccosa Rs is separated from $\mathrm{M}$ and cannot be considered as the fore branch of $\mathrm{M}$. 
Thus, there cannot be any doubt about the fact that, in the hind wings of the Manteodea, the vein which is situated behind R is Rs, which is characteristic also for the hind wings of the Paleozoic and Mesozoic Blattodea.

In the hind wings of the Manteodea a free base of MP, which Smart (I956) designates as the "oblique cross-vein", is preserved. Among the Polyneoptera a similar vein is preserved in the hind wings

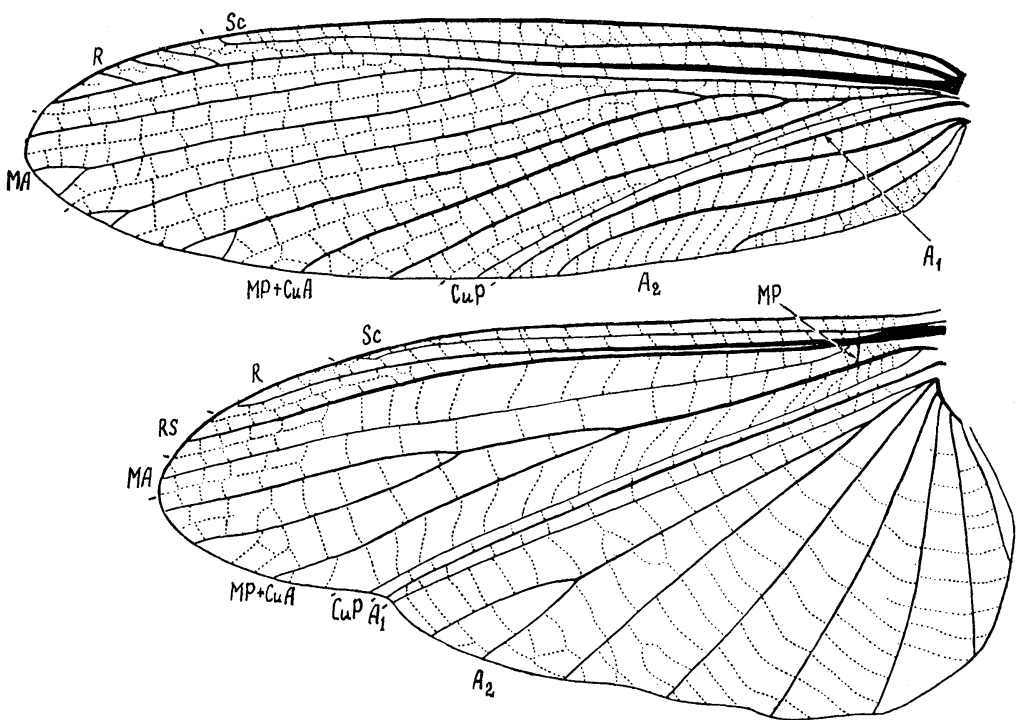

Fig. 2. Drawing of the fore and hind wings of Chaeteesa filata Burm. (After Smart, 1956, with changed designations of the veins.)

of Plecoptera and Orthoptera. Its homology with the same vein in the fore wings, in the cases where it is preserved, seems obvious.

\section{Acknowledgements}

I wish to thank Professor F. M. Carpenter and Dr. Hugo Rodeck (University of Colorado) for giving me the opportunity to study the holotype of $L$. floccosa and for the photographs of this fossil insect, which were used for the preparation of the drawings. I am very grateful also to Dr. G. M. Byers for sending the specimen of the hind wing of this insect.

ChOPARD, L.

\section{Literature Cited}

1949. Ordre des Dictyoptères. In P. P. Grasse, Traité de Zoologie 9, Masson, pp. 353-407. 
Cockerell, T. D. A.

1908. The first American fossil Mantis. Canad. Ent. 40:343-344. RAGGE, D. R.

1955. The wing venation of the Orthoptera Saltatoria with notes on Dictyopteran wing venation. British Museum (Nat. Hist.), pp. 1-159.

Sharov, A. G.

1960. The origin of the order Plecoptera. Verh. XI. Int. Kongr. Ent., SMART, J. Wien, 1960, 1:296-298.

1956. On the wing venation of Chaeteesa and other mantids (Insecta Mantodea). Proc. Zool. Soc. London 127: 545-553. 

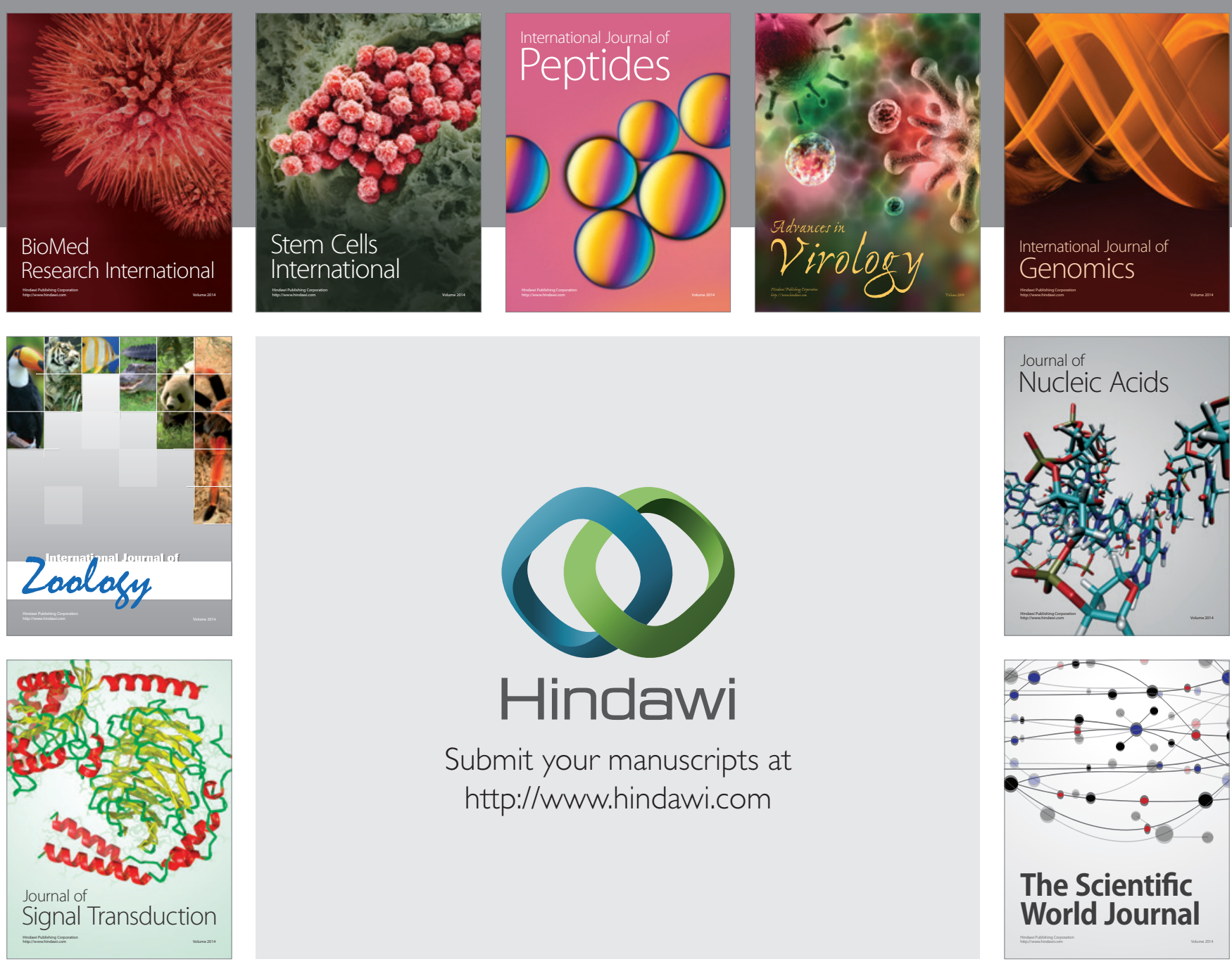

Submit your manuscripts at

http://www.hindawi.com
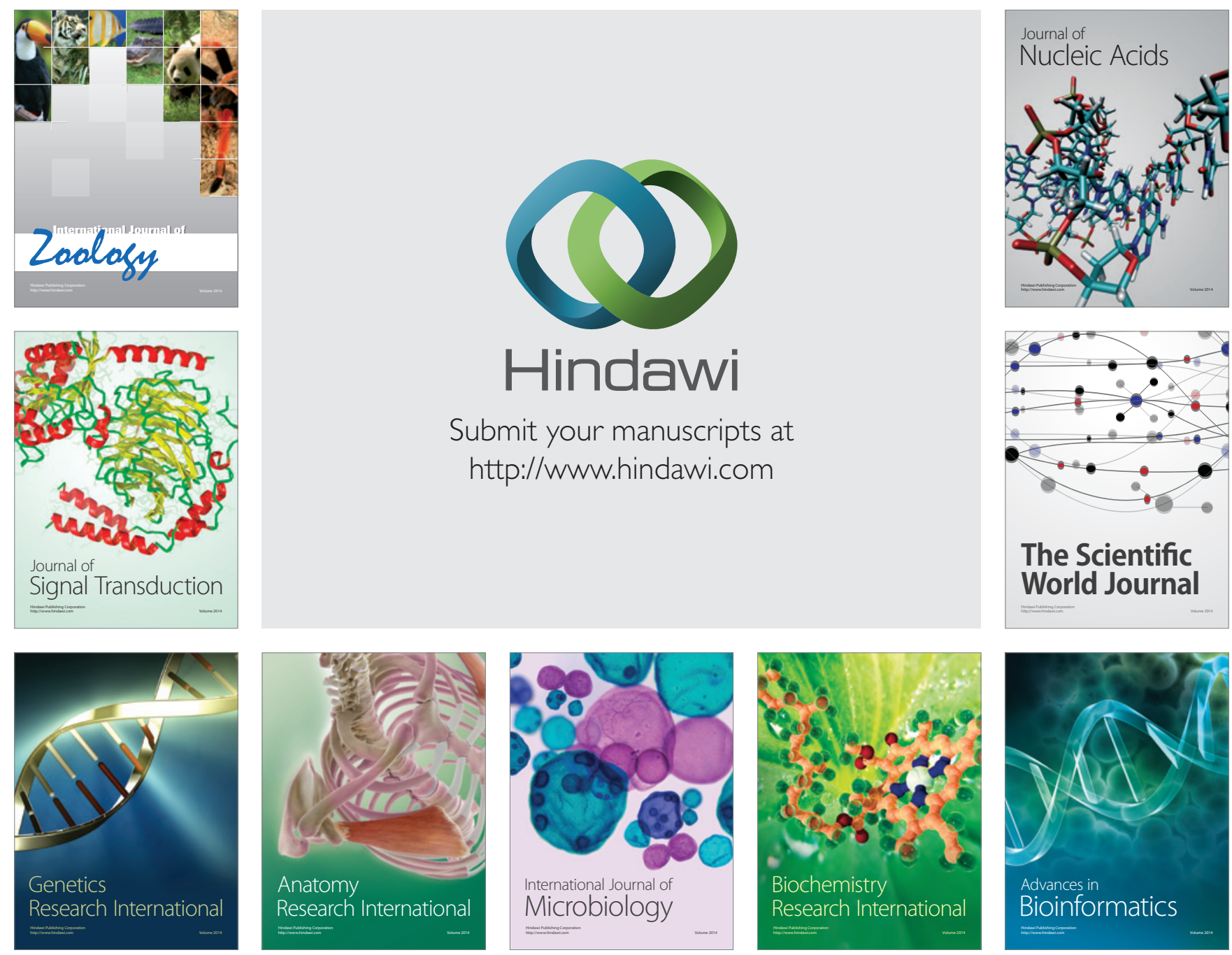

The Scientific World Journal
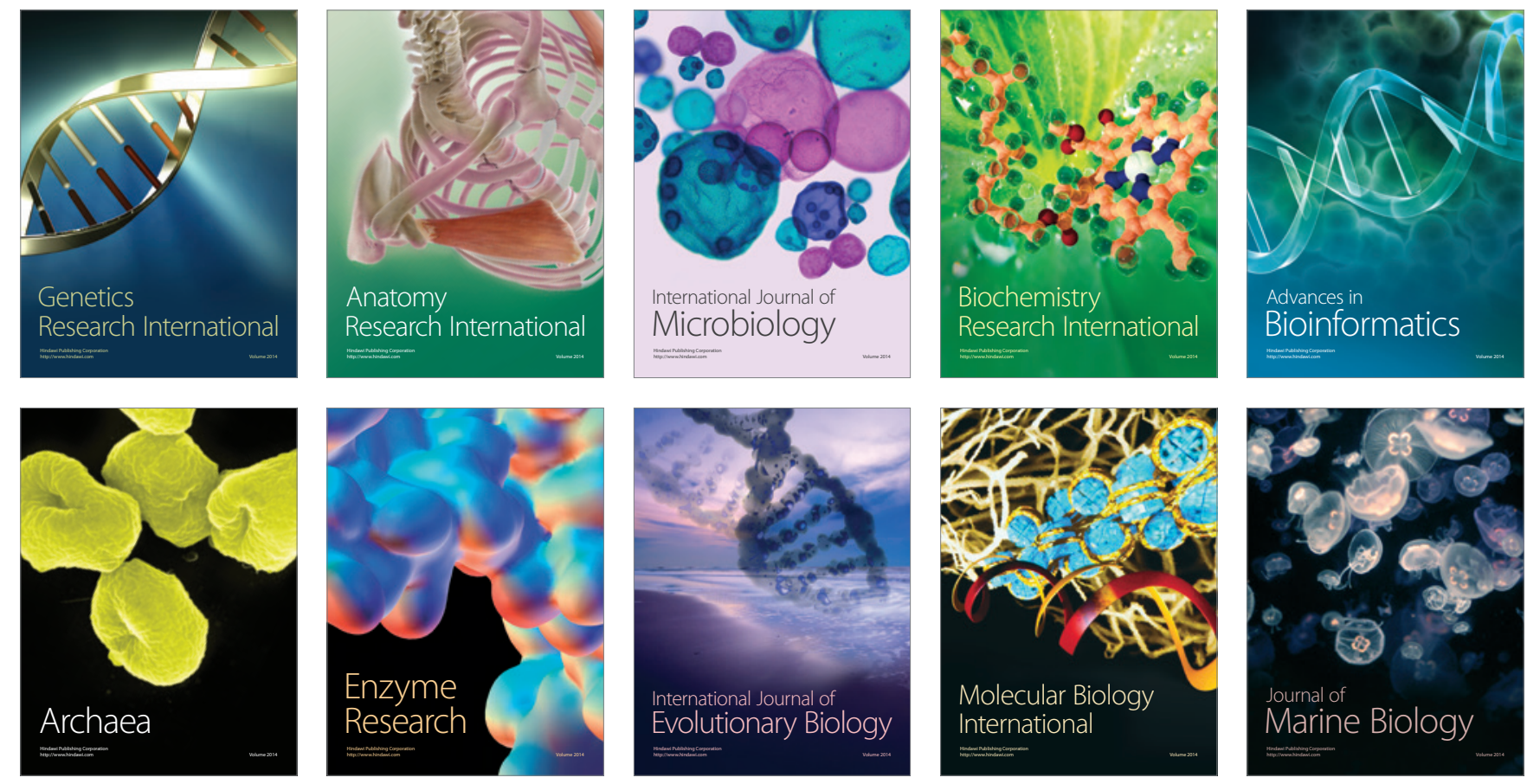